\title{
A hipótese da gramática universal e a aquisição de segunda língua
}

\author{
Andréa Machado de Almeida Mattos \\ Universidade Federal de Minas Gerais
}

\section{Abstract}

The aim of this paper is to present the theory of second language acquisition based on the Universal Grammar (UG) Hypothesis. At first, the main aspects related to the scope of the Generative Theory are presented, introducing its main ideas. Then, the main points of the theory of second language acquisition based on the UG are presented, considering some controversial issues and its basic problems. Finally, the paper tries to critically discuss some of the theory's obscure points, offering alternative solutions and opinions. 


\section{INTRODUÇÃO}

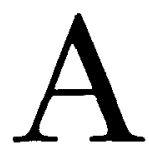

Lingüistica Aplicada tem uma história bastante recente no cenário científico mundial. O desenvolvimento da disciplina data do final dos anos 50, com a inauguração da School of Applied Linguistics, na Universidade de Edinburgh, no Reino Unido, em 1956, e a abertura do Center for Applied Linguistics, em Washington, nos Estados Unidos, em 1959 (KAPLAN, 1993). O termo Lingüística Aplicada é muitas vezes confundido com o campo da pesquisa em aquisição de segunda língua que, segundo KAPLAN (1993:375), tornou-se uma área independente nos últimos anos. Contudo, VAN LIER (1994:329) considera esta separação contraprodutiva. No Brasil, a Lingüística Aplicada data de 1970, quando da criação do Programa de Estudos Pós-Graduados em Lingüística Aplicada ao Ensino de Línguas, da PUC-SP (CELANI, 1992), e certamente mantém, até hoje, uma forte interseção com a pesquisa em aprendizagem de língua estrangeira, embora não se restringindo a ela.

O escopo do presente trabalho, porém, restringe-se ao campo da pesquisa em aquisição de segunda língua ${ }^{1}$ (L2), mais precisamente ao âmbito das teorias sobre aquisição de L2. Aqui, também, há grandes controvérsias. Para alguns teóricos da área, o número de teorias sobre aquisição de L2 varia entre 40 e 60 , incluindo "teorias, hipóteses, modelos, metáforas, arcabouços teóricos e perspectivas" (LONG, 1993:225). ${ }^{2}$ Para outros (como GREGG, 1993; VAN LIER, 1994) este número não passa de cinco. Numa rápida revisão da literatura pertinente (ELLIS, 1985 e 1997; KLEIN, 1986; MCLAUGHLIN, 1987; LARSEN-FREEMAN \& LONG, 1991), verifica-se que, dentre as teorias de maior repercussão, encontram-se: o Modelo de Aculturação, de Schumann; os Estudos sobre Interlíngua, termo cunhado 
por Selinker para definir a língua do aprendiz; o Modelo do Monitor, de Krashen, com suas cinco hipóteses, que talvez seja o modelo de maior penetração na área do ensino de segunda língua; e a Hipótese da Gramática Universal, baseada nos estudos da escola chomskiana sobre aquisição de língua materna (L1). A lista, obviamente, não se esgota aqui, nem tampouco estas teorias, que, por serem mais famosas e talvez mais abrangentes, estão livres de críticas e questionamentos. O presente trabalho tem por objetivo apresentar a teoria de aquisição de segunda língua com base na Hipótese da Gramática Universal (GU), discutir o chamạdo "problema da aquisição de segunda língua", que será apresentado no decorrer do texto a seguir, e fazer algumas reflexões sobre pontos obscuros ou controversos já apontados na teoria.

\section{A HIPÓTESE DA GRAMÁTICA UNIVERSAL}

Até meados dos anos 50, pressuposições de bases teóricas behavioristas dominavam o campo da Lingüística Aplicada. Skinner, o pai do Behaviorismo, sustentava que a aquisição da linguagem pela criança era feita através da imitação do comportamento dos adultos e da formação de hábitos - ditos lingüísticos. A língua seria, então, um conjunto de hábitos adquiridos através do modelo "estímuloresposta", ou seja, a criança aprende a forma "correta" da língua quando é recompensada pela produção de um comportamento lingüístico correto e punida pela produção de um comportamento lingüístico incorreto (KAPLAN, 1985).

Em 1959, CHOMSKY publicou Review of B. F. Skinner: verbal behaviour, que provocou uma revolução na Lingüistica Aplicada. Chomsky sustentava, contrariamente a Skinner, que "as crianças nascem com uma predisposição natural biologicamente condicionada para a aquisição da linguagem e que a simples exposição a uma língua é suficiente para desencadear o seu processo de aquisição" (KAPLAN, 1985:2).

Esta visão da linguagem deu origem à teoria lingüística chamada Gramática Gerativa, desenvolvida por Chomsky e seus 
seguidores desde 1957 e cujo objeto de estudo é a Gramática Universal (GU), ou seja, "os aspectos sintáticos que são comuns a todas as línguas do mundo" (VITRAL, 1998:120). Para os seguidores desta teoria, portanto, a criança nasce com uma predisposição natural para a aprendizagem da sua língua materna. Esta predisposição natural é exatamente o que chamam de Gramática Universal, um conjunto de princípios e parâmetros que permitem a uma criança normal o desenvolvimento da linguagem durante os seus primeiros anos de vida, a partir da exposição à sua língua materna. Na visão dos pesquisadores desta linha, os princípios são responsáveis pelos aspectos comuns a todas as línguas humanas e os parâmetros explicam a variação encontrada entre as línguas.

Os teóricos desta linha, também chamados "gerativistas" ou "inatistas", defendem que há duas evidências que comprovam a hipótese da Gramática Universal. A primeira delas é "o trabalho empírico de análise de línguas, no qual se procura estabelecer regularidades entre as línguas e, a partir dessas regularidades, princípios que as expliquem" (VITRAL, 1998:122). A segunda evidência se baseia na aquisição da linguagem pela criança. Como já foi dito, acredita-se que o ambiente lingüístico ao qual a criança é exposta apenas ativa suas estruturas lingüísticas inatas, permitindo o desenvolvimento da linguagem. Além disso, toda criança normal, independentemente da sua classe social ou do grau de estimulação que recebe, é capaz de aprender sua língua materna nos primeiros anos de vida (entre 1 e 4 anos de idade) e esta aprendizagem é completa, ou seja, a criança aprende todo o sistema lingüístico de sua língua (VITRAL, 1998:123).

Este seria, então, o chamado "problema da aquisição da linguagem". Estudos sobre o ambiente lingüístico ao qual a criança está exposta mostraram que o input recebido é insuficiente para a aquisição da linguagem. WHITE (1989a) apresenta três problemas desse input: a subdeterminação, a degeneração e a ausência de evidência negativa. A subdeterminação se refere ao fato de que vários aspectos da língua são subdeterminados pelo input, isto é, o 
conhecimento que a criança adquire da sua língua, chamado de competência lingüística, inclui noções que não são óbvias no input recebido e que não são ensinadas diretamente. $O$ conhecimento implícito subjacente ao uso da linguagem vai muito além daquilo a que uma criança qualquer estaria realmente exposta, e este conhecimento não poderia ser adquirido através de estratégias gerais de aprendizagem ou habilidades de solução de problemas. A degeneração se refere ao fato de que o input que a criança recebe nem sempre é perfeito. Na verdade, este input é cheio de erros, hesitações e interrupções, incluindo frases agramaticais e formas parciais tanto quanto frases gramaticais. A ausência de evidência negativa, ou seja, ausência de informações explícitas sobre que frases seriam agramaticais, constitui um outro problema para a aprendizagem da língua. Pesquisas sobre aquisição de língua materna sugerem que as crianças geralmente não são corrigidas quando produzem uma frase agramatical. Este tipo de evidência, portanto, não estaria presente no input recebido pelas crianças mas apenas evidências positivas na forma de frases gramaticais (ou quase) realmente ouvidas pelas crianças.

Apesar desses problemas, toda criança normal é capaz de aprender sua língua materna num período de tempo surpreendentemente curto e normalmente consegue se comunicar livremente já na idade pré-escolar (KLEIN, 1986:3). Chomsky propôs que isso é possível porque a Gramática Universal tem uma base biológica, ou seja, mecanismos inatos da mente da criança que permitem a aquisição da linguagem. Esses mecanimos constituiriam os princípios e parâmetros da Gramática Universal e estariam presentes na forma de estruturas mentais inatas, que foram chamadas de Dispositivo de Aquisição da Linguagem. Esse dispositivo conteria os princípios universais inerentes a todas as línguas humanas e também os parâmetros universais que permitem suas variações e, por isso, seria responsável por construir a competência lingüística da criança a partir dos dados lingüísticos do input. Segundo COOK (1983:16), esse dispositivo mental 
"é específico para linguagem; ele trabalha de maneira bem diferente de outras formas de aprendizagem e leva a um tipo de conhecimento que é distintamente lingüístico ao invés de compartilhar propriedades com outros aspectos do conhecimento."

\section{O PROBLEMA DA AQUISIÇĀO DE SEGUNDA LÍNGUA}

O problema da aquisição de segunda língua segue o mesmo raciocínio apresentado para o problema da aquisição da linguagem. WHITE (1989a:37) sustenta que, assim como a criança, "o aprendiz de uma segunda língua também enfrenta o problema de extrair sentido de dados lingüísticos, de produzir um sistema que explique tais dados e que lhe permita compreender e produzir estruturas na L2". Para os pesquisadores interessados em aquisição de segunda língua que trabalham sob o referencial teórico da Gramática Gerativa, um aprendiz de segunda língua, enfrenta esse problema com as mesmas ferramentas utilizadas por uma criança ao aprender sua língua materna, ou seja, os princípios e parâmetros da Gramática Universal, disponíveis no seu Dispositivo de Aquisição da Linguagem. Assim como na aprendizagem da língua materna, o input disponível para o aprendiz de L2 é considerado insuficiente para que a partir dele o aprendiz consiga construir todo o sistema de uma língua. Portanto, para que possa adquirir uma língua estrangeira, o aprendiz, assim como a criança, fará uso da Gramática Universal.

WHITE (1989a:38) chama atenção para duas alternativas: em primeiro lugar, o fato de que o problema da aquisição de segunda língua possa talvez ser resolvido sem o uso da Gramática Universal, mas através do uso de conhecimentos advindos da língua materna do aprendiz; em segundo lugar, o problema pode, na verdade, nunca ser resolvido, já que a maioria dos aprendizes de L2 não conseguem chegar a níveis avançados de domínio da língua estrangeira e jamais chegam a desenvolver um sistema lingüístico que seja qualitativamente superior ao input recebido. Mesmo assim, White advoga a idéia de que o input da L2 subdetermina o sistema lingüístico desenvolvido pelo aprendiz de L2, da mesma forma que o input da 
L1 subdetermina o sistema lingüístico desenvolvido pela criança. Sobre a questão da degeneração do input recebido, White sustenta que, apesar de algumas pesquisas demonstrarem que o input disponível para o aprendiz de L2 não é degenerado, mas sim simplificado na forma de teacber-talk foreigner-talk, isto apenas complica o problema, pois input simplificado também seria insuficiente para permitir a aquisição do sistema da L2. A diferença principal entre a aprendizagem de $\mathrm{L} 1$ e L2, no que se refere ao input disponível ao aprendiz, estaria na presença da evidência negativa, ou seja, enquanto crianças aprendendo uma língua materna recebem pouca ou nenhuma evidência negativa, é indiscutível que os aprendizes de língua estrangeira têm acesso à evidência negativa em aulas de língua. Além disso, segundo BLEY-VROMAN (1989:48), "entre aprendizes e professores de línguas estrangeiras há em geral uma aceitação de que a evidência negativa é pelo menos algumas vezes útil, e algumas vezes, porém nem sempre, necessária." Contudo, WHITE (1989a:40-1) discorda de que a presença da evidência negativa leve à conclusão de que aprendizes de L2 não se utilizam da Gramática Universal. Em primeiro lugar, para que a evidência negativa seja eficaz, é necessário que o aprendiz faça uso dela. White defende que nem todo aprendiz de $\mathrm{L} 2$ recebe evidência negativa e que aqueles que recebem nem sempre se utilizam dela. White lembra que ninguém pode ser corrigido por erros que não cometeu: do mesmo modo como crianças aprendem sua língua materna, o aprendiz de L2 não parece cometer erros que violem a Gramática Universal.

\section{A QUESTĀO DO ACESSO À GRAMÁTICA UNIVERSAL}

Como já foi dito, existem várias teorias sobre a aquisição de língua estrangeira, e a Hipótese da Gramática Universal é apenas uma delas. Contudo, mesmo entre aqueles que defendem a idéia de que a espécie humana dispõe de uma capacidade inata para a aquisição da linguagem, no âmbito da aquisição de segunda língua, 
há divergências. A principal delas é a questão do acesso à Gramática Universal, ou seja, até que ponto um aprendiz de segunda língua continua tendo acesso aos princípios e parâmetros da GU. ELLIS (1997:69) lista quatro posições teóricas contraditórias, o que comprova que o papel da GU na aquisição de língua estrangeira ainda é incerto. Vejamos quais são estas posições:

1. Acesso total $\rightarrow$ Esta posição assume que o processo de aquisição de uma segunda língua é idêntico ao processo de aquisição de língua materna e os aprendizes, portanto, têm total acesso à Gramática Universal. A aquisição do sistema da L2 seria, então, puramente resultado da interação entre a GU e os dados da L2 e a língua nativa não traria nenhum efeito para o processo de aquisição. Neste caso, seria possível para um aprendiz de língua estrangeira atingir um comando aproximadamente nativo da língua em questão.

2. Nenbum acesso $\rightarrow$ Esta posição assume que a GU não está mais disponível para os aprendizes de L2, pelo menos para os adultos. Estes fariam uso de estratégias gerais de aprendizagem não específicas para a aquisição da linguagem, o que explicaria a variação no grau de sucesso obtido na aquisição de L2. Neste caso, aprendizes adultos normalmente não conseguiriam atingir um comando avançado da língua alvo e suas interlínguas poderiam conter regras que seriam proibidas pela $\mathrm{GU}$.

3. Acesso parcial $\rightarrow$ Esta posição assume que os aprendizes de L2 somente têm acesso aos parâmetros da GU que estão em operação na sua língua materna. Contudo, seria possível reativar os parâmetros relevantes para a L2 através da instrução formal e da correção de erros. Assim, nesta visão a aquisição da língua estrangeira seria parcialmente regulada pela GU e parcialmente por estratégias gerais de aprendizagem.

4. Acesso dual $\rightarrow$ De acordo com esta visão, aprendizes adultos de L2 fazem uso tanto da GU quanto de estratégias gerais de aprendizagem. Contudo, o uso de estratégias gerais de aprendi- 
zagem pode bloquear o acesso à GU. Neste caso, os aprendizes não atingiriam um comando nativo da língua alvo e também poderiam produzir erros inaceitáveis pela GU.

\section{AS DIFERENÇAS ENTRE OS PROCESSOS DE AQUISIÇÃO DE L1 E L2}

Comparando o processo de aquisição de língua materna com o processo de aquisição de língua estrangeira, especialmente na idade adulta, é possível notar várias diferenças. BLEY-VROMAN (1989:43-8) aponta oito diferenças fundamentais entre estes dois processos, além da questão da ausência/presença da evidência negativa, já comentada anteriormente. São elas:

1. Falta de sucesso $\rightarrow$ Crianças normais sempre atingem um perfeito comando do sistema lingüístico da sua língua materna. O mesmo não se pode dizer de aprendizes adultos de segunda língua que, ao contrário, não conseguem obter sucesso perfeito ao aprender uma L2.

2. Falência geral $\rightarrow$ Não só a falta de sucesso é uma característica da aprendizagem de L2 entre aprendizes adultos, como também a falência é geral, ou seja, o sucesso completo é extremamente raro entre aprendizes adultos de L2, principalmente no que se refere ao sotaque e às intuições sobre gramaticalidade.

3. Variação no sucesso, curso e estratégia $\rightarrow$ Entre crianças, o grau de sucesso na aprendizagem, o curso da aprendizagem e as estratégias utilizadas são uniformes, isto é, toda criança normal aprende sua língua materna com sucesso total, seguindo aproximadamente um mesmo curso e utilizando as mesmas estratégias. Entre adultos, o grau de sucesso varia substancialmente, mesmo quando outras variáveis como idade, quantidade de exposição à língua alvo, instrução formal, etc. são mantidas estáveis. Além disso, aprendizes diferentes seguem rotas diferentes e aprendem estruturas e subsistemas em ordens diferentes. Por fim, as estratégias utilizadas por aprendizes adultos também variam de aprendiz para aprendiz. 
4. Variação nos objetivos $\rightarrow$ Entre aprendizes adultos de L2, há também grande variação nos objetivos de cada aprendiz. Alguns desenvolvem muita fluência na segunda língua, mas atingem um baixo nível de competência; outros preocupam-se com a correção gramatical, embora não sejam muito fluentes; outros, ainda, podem preocupar-se mais com uma boa pronúncia ou com o desenvolvimento lexical. Alguns podem ter por objetivo serem confundidos com um nativo. Outros orgulham-se de se mostrarem estrangeiros.

5. Fossilização $\rightarrow$ Este é um fenômeno típico da aprendizagem de língua estrangeira na fase adulta. É sabido que aprendizes adultos atingem um determinado grau de desenvolvimento na $\mathrm{L} 2$ - bem inferior ao nível atingido pelo nativo - e depois permanecem estáveis neste nível, sem prosseguir no desenvolvimento da aprendizagem da língua.

6. Intuições indeterminadas $\rightarrow$ Vários estudos demonstram que mesmo os mais competentes aprendizes de L2 não conseguem fazer julgamentos de gramaticalidade com clareza. Este caráter opaco das intuições sobre gramaticalidade entre falantes nãonativos foi chamado de indeterminado (SCHACHTER, TYSON \& DIFFLEY, 1976, apud BLEY-VROMAN, 1989:47).

7. Importância da instrução $\rightarrow$ Crianças em fase de desenvolvimento da linguagem não necessitam de instrução formal para aprender sua língua. No entanto, há consenso quanto à influência positiva da instrução formal na aprendizagem de L2 entre adultos.

8. Papel dos fatores afetivos $\rightarrow$ O sucesso da aprendizagem da língua materna entre crianças parece não ser afetado por fatores como personalidade, socialização, motivação e atitude. A aprendizagem de uma língua estrangeira por adultos, pelo contrário, parece ser altamente influenciada por tais fatores, ditos afetivos.

Com base nessas diferenças, Bley-Vroman propõe a Hipótese da Diferença Fundamental, ou seja, crianças e adultos adquirem o uso da linguagem (L1, para a criança e L2, para o adulto) de maneiras 
fundamentalmente diferentes. Para ele, as características da aquisição da linguagem pelo adulto acima descritas são características gerais de aprendizagem, que incluem estratégias cognitivas gerais para solução de problemas. Assim, BLEY-VROMAN (1989:51) sustenta que a aquisição de uma segunda língua por um adulto é baseada no conhecimento da sua língua nativa e em sistemas gerais de solução de problemas, ao contrário da criança que se baseia na GU e em procedimentos de aprendizagem específicos para o domínio da linguagem. Bley-Vroman justifica, assim, o insucesso geral da aquisição de segunda língua por adultos, pois, para ele

"a linguagem não é meramente difícil de se aprender usando-se somente estratégias gerais de aprendizagem, mas sim virtualmente impossível. Esta é uma razão importante para se atribuir às crianças uma faculdade inata específica para o desenvolvimento da linguagem." (1989:44).

\section{OS PRINCIPAIS PROBLEMAS DA TEORIA}

Apesar de bastante difundida e amplamente aceita atualmente, com vários pesquisadores renomados interessados em decifrar tanto o problema da aquisição da linguagem (L1) quanto o problema da aquisição de segunda língua, a teoria lingüística que trabalha com a Hipótese da Gramática Universal e as pesquisas nela baseadas, principalmente no âmbito da aquisição de L2, não estão livres de problemas. Vejamos alguns apontados por ELLIS (1994):

\section{- Quanto ao domínio da teoria}

A teoria de aquisição de L2 baseada na Hipótese da Gramática Universal dedica-se a estudar um fenômeno bastante restrito, ou seja, a competência gramatical desenvolvida a partir de um conhecimento inato e abstrato sobre os princípios e parâmetros que determinam as possibilidades de realização da linguagem humana. Deste domínio restrito, muitos pontos são excluídos e fica claro que a teoria deixa de analisar aspectos cruciais da linguagem e do seu uso, cobrindo 
apenas parte do fenômeno total de desenvolvimento da linguagem humana que deveria ser estudado por uma teoria abrangente. Contudo, enquanto para alguns este é um problema, para outros o fato de o domínio da teoria ser tão bem definido é uma grande vantagem, pois permite delimitar o campo da pesquisa a proporções manuseáveis (ELLIS: 461).

\section{- Quanto aos problemas metodológicos}

Os problemas relacionados à metodologia das pesquisas realizadas nesta área são vários. Em primeiro lugar, as pesquisas têmse restringido a estudos trans-seccionais de vários sujeitos e faltam estudos longitudinais. Um outro problema se refere ao fato de que estas pesquisas, em sua grande maioria, têm-se baseado em testes de julgamentos de gramaticalidade realizados pelos sujeitos. Já que as pesquisas sobre a aquisição de L2 preocupam-se principalmente com o aprendiz adulto, um outro problema importante refere-se à definição de "adulto" e à determinação de quando começa a idade adulta.

\section{- Quanto aos resultados das pesquisas}

Os resultados das pesquisas sobre a aquisição de segunda língua feitas com base na Hipótese da Gramática Universal têm-se mostrado indeterminados. Os estudos sobre a acessibilidade da GU na aquisição de L2 por adultos parecem mostrar que os aprendizes têm pelo menos acesso parcial à $G U$, porém conclusôes mais específicas não são possíveis (ELLIS, 1994: 458). Exemplos destas pesquisas podem ser encontrados em GASS \& SCHACHTER (1989), onde são relatados vários estudos sobre aquisição de L2 com base na GU que tentam derivar conclusões sobre a acessibilidade à gramática universal durante a aquisição de uma segunda língua. SCHACHTER (1989) conclui que, na idade adulta, o aprendiz demonstra ter acesso apenas aos parâmetros da GU que estão presentes na sua língua materna. Outro tipo de conclusão apresen- 
tada por estes estudos parece indicar que a língua materna pelo menos influencia a aquisição de L2: FLYNN (1989) conclui que nas estruturas sintáticas onde os parâmetros da L1 e da L2 são os mesmos, a aquisição é facilitada, porém, nas estruturas em que estes parâmetros diferem, a aquisição parece ser mais árdua; LICERAS (1989) sugere que a distância entre as línguas (L1 e L2) pode ter um papel determinante na interpretação das estruturas; WHITE (1989b) sugere que os parâmetros da L1 influenciam a marcação dos parâmetros da L2, e GASS (1989) sugere que a fonte inicial da formação de hipóteses na L2 pode ser a L1 e apenas onde há divergência os aprendizes recorrem à gramática universal. Contudo, mesmo conclusões desse tipo não são totalmente corroboradas pelos resultados.

\section{- Quanto aos problemas teóricos}

Os principais problemas teóricos desta linha de pesquisa se referem à definição dos parâmetros universais e de suas características gramaticais. A contínua revisão da teoria quanto a estas questões torna-se um problema para os pesquisadores de L2, pois trabalham com um modelo em constante evolução, que pode se tornar obsoleto antes que suas pesquisas estejam terminadas. Um problema mais sério, porém, é a impossibilidade de se determinar se os aprendizes estão ou não se comportando de acordo com a GU (ELLIS, 1994:459). Isto fica claro quando se analisam os resultados das pesquisas acima citadas.

\section{REPENSANDO ALGUMAS IDÉIAS}

Além dos problemas apontados acima, um leitor atento e informado fará com certeza suas próprias observações e analisará a teoria do ponto de vista da sua aplicabilidade prática. Como aponta BEAUGRANDE (1997:280), "até que ponto uma teoria é válida na prática é uma boa medida de até que ponto a teoria é válida enquanto teoria". Na verdade, não se trata de dizer que a teoria é válida ou inválida. Porém, tenta-se, aqui, discutir pontos já indicados 
como obscuros ou controversos por autores renomados, retomandose esses pontos pela ótica do chamado insider. ${ }^{4}$

Tomando-se como ponto de partida, então, as palavras de Beaugrande citadas acima, uma pergunta pertinente seria qual a real aplicabilidade dos estudos baseados na Hipótese da Gramática Universal para a construção de uma teoria sobre aquisição de segunda língua, já que, como sugere GREGG (1984:79), "a aquisição de uma segunda língua pode ser simplesmente muito difícil e muito complexa para ser tratada por única teoria". Alguns autores, como LONG (1990) e o próprio BEAUGRANDE (1997), já tentaram estabelecer os pontos que deveriam ser abordados por uma teoria abrangente sobre a aquisição de segunda língua. No entanto, as teorias disponíveis hoje em dia, inclusive a Teoria Gerativista, parecem não satisfazer totalmente esses requisitos.

Para começar, os pesquisadores gerativistas trabalham com dados idealizados, ou seja, a competência lingüística de "um falanteouvinte ideal numa comunidade lingüística completamente homogênea, que sabe a sua língua com perfeição" (CHOMSKY apud HYMES, 1972). Tal fonte de dados não leva em consideração que a linguagem humana faz parte de um sistema unificado de comportamento e que a formação de frases de uma língua não é determinada exclusivamente por regras lingüísticas, mas também por restrições cognitivas (como memória e atenção) e sociais ou contextuais (BEAUGRANDE, 1997). A Teoria Gerativista, como já foi dito, postula que a aquisição da linguagem é determinada biologicamente e é geneticamente transmitida na forma de capacidades inatas da espécie humana, desconsiderando processos de aquisição derivados da experiência de situações da vida real e de aprendizagem explícita. Além disso, os gerativistas desconsideram o papel da comunicação na aquisição da linguagem. GREGG (1989) afirma que a forma da linguagem humana independe de sua função, e que o objetivo essencial da linguagem não é a comunicação. No entanto, este não é um ponto pacificamente aceito por outras linhas de pesquisa, como por exemplo, a Abordagem Funcionalista e a Teoria Construtivista, 
que atribuem à comunicação um papel crucial no desenvolvimento da linguagem.

Justamente por menosprezar grande parte dos processos e estratégias gerais que, em princípio, poderiam ser utilizados na aquisição de uma língua é que a Teoria Inatista necessita de postular a existência do Dispositivo de Aquisição da Linguagem, pois, de que outra maneira poderia, então, uma criança desenvolver um sistema lingüístico completo, em tão pouco tempo, se já não tivesse sido preparada biologicamente para isto? Porém, apesar de esta idéia fazer algum sentido e de muitos pesquisadores e professores de língua terem aderido a ela, este poderoso dispositivo cujo mecanismo de operação é capaz de fazer a mediação entre o input recebido e o sistema lingüístico resultante, jamais foi apropriadamente descrito. A definição atual dos mecanismos inatos de aquisição da linguagem é a Teoria de Princípios e Parâmetros que tenta descrever o conteúdo da chamada Gramática Universal. Segundo VITRAL (1998:125-6), "hoje em dia começa-se a desenvolver a idéia segundo a qual as restrições impostas pela Gramática Universal seriam, na verdade, decorrentes da natureza das características físicas do cérebro." Muitos pesquisadores, porém, rejeitam a idéia de que a aquisição da linguagem se dê num órgão mental específico $\left(o\right.$ LAD $\left.^{5}\right)$. KLEIN (apud ELLIS, 1994) argumenta que a existência desse órgão mental é uma postulação desnecessária, já que todo o processo de aquisição, a seu ver, pode ser explicado sem a pressuposição de uma capacidade cognitiva extra, específica para a linguagem. Contra a evidência do total sucesso das crianças em aprender sua língua materna num curto espaço de tempo, ELLIS (1994:461) sugere que "isto apenas demonstra que as crianças têm uma notável capacidade para a aprendizagem de línguas, que pode ser especificamente lingüística ou mais genericamente cognitiva por natureza".

Um outro debate importante está relacionado à influência dos fatores afetivos na aquisição da linguagem. Parece ser ponto pacífico, no campo da Língüística Aplicada, que esses fatores não influenciam a aquisição de língua materna mas, como já foi dito, tais fatores 
parecem influenciar grandemente a aquisição de uma língua estrangeira, principalmente na idade adulta. Contudo, BEAUGRANDE afirma que, em relação às habilidades cognitivas gerais,

"pesquisas empíricas sobre cognição já estabeleceram firmemente
que tanto a aprendizagem quanto o desempenho são na verdade
significativamente facilitados por fatores como motivação, auto-
confiança e um senso de pertencer ao grupo, e prejudicados por
ansiedade e postura defensiva, sentimentos de fraqueza e
expectativas de insucesso" (1997:301).

Ora, se há evidências empíricas que comprovem a influência de fatores afetivos nas capacidades cognitivas humanas em geral, não há motivo para supor que a capacidade de aquisição da linguagem seria uma exceção. Beaugrande conclui que "modelos que, como [a Gramática Gerativa], deixam de lado fatores como limitações de memória, distrações e mudanças de foco de atenção, são irrealistas e improdutivos" (1997:302) e, além disso, não podem ser testados.

Como já foi dito, os pesquisadores gerativistas acreditam que uma criança, ao aprender sua língua materna, não produz erros proibidos pelos princípios da GU. Da mesma forma, para aqueles que acreditam que a GU continua disponível para a aquisição de segunda língua, aprendizes de L2 também não produzem erros que violem estes princípios. Sobre isto, WHITÉ (1989a:55) cita pesquisas recentes que sugerem que "alguns princípios da GU emergem de acordo com um programa maturacional." Assim, o sistema lingüístico de uma criança poderia apresentar erros que violem princípios ainda não maturados. White presume, assim como COOK (1994), que esta questão é irrelevante para a aprendizagem de L2, já que todos os princípios já teriam sido maturados durante a aquisição da L1. Não parece ter sido conjecturado, porém, que a maturação de tais princípios talvez seja estimulada pelo próprio desenvolvimento da L1 e, portanto, uma determinada língua poderia apresentar princípios maturacionais diferentes de uma outra. Nesse caso, esses princípios poderiam ser uma boa explicação para o insucesso constatado entre aprendizes de L2, já que, num adulto, os princípios maturados 
durante a aquisição da sua L1 poderiam ser diferentes daqueles necessários para a aquisição da L2.

Finalmente, um ponto que parece inquestionável é a constatação de que poucos aprendizes de L2 chegam a adquirir a língua alvo com domínio nativo ou quase-nativo. É fato notório que a esmagadora maioria não passa de níveis intermediários de proficiência na L2. Como foi visto, entre os pesquisadores gerativistas, essa situação é debatida em termos das diferentes hipóteses de acesso aos princípios da GU na idade adulta, porém há várias explicações alternativas. Schumann (apud ELLIS, 1985) sugere a questão da aculturação; KRASHEN (1985) afirma que a resposta está na quantidade insuficiente e na qualidade inferior do input recebido por aprendizes de L2 em contextos não-naturalistas, além de propor as hipóteses do filtro afetivo e do monitor; GARDNER \& LAMBERT (1972) propõem que o tipo de motivação - integrativa ou instrumental - estaria ligado a um maior ou menor sucesso na aquisição. Uma outra explicação comumente aceita seria a idade do aprendiz quando do início de sua exposição à língua alvo, interrelacionada com o tempo de exposição. A idade ideal para se começar a aprender uma L2 é um ponto amplamente discutido no campo da pesquisa em aquisição de segunda língua, porém é ponto pacífico que quanto maior o tempo de exposição à língua, maior será o sucesso do aprendiz.

Uma questão que parece não ter sido ainda levantada como explicação para o insucesso do aprendiz de L2 é o fato de que, por mais que ele se exponha (ou esteja exposto) à língua alvo, esta será sempre sua segunda língua. A língua nativa parece permear toda a cognição do ser humano. KLEIN (1986:5) afirma que

"existem elementos cruciais no controle da linguagem que estão interrelacionados com o desenvolvimento da criança e que são adquiridos durante a aprendizagem da primeira língua, ficando depois disponíveis para a aquisição de L2."

O desenvolvimento cognitivo da criança estaria, assim, intimamente ligado ao desenvolvimento da linguagem, e transferir ou ajustar para 
a L2 os conceitos cognitivos já existentes em L1 pode ser "uma tarefa particularmente árdua para o aprendiz" (KLEIN, 1986:5)

Assim, pode-se supor que os aprendizes de L2 não cheguem a níveis avançados de proficiência na segunda língua porque continuam usando sua língua materna em seus processos cognitivos de alto nível, quando não estão em contato direto com a L2, ou seja, quando não estão realizando alguma tarefa na L2. O que se está querendo dizer é que o ser humano estará usando a sua língua materna automaticamente - ou seja, involuntariamente - em qualquer situação em que se encontre, mesmo que não seja uma situação ligada à realização de uma tarefa que exija um processamento lingüístico, e somente usará a L2 quando a situação se lhe impuser. É ainda Klein que levanta a questão da dominância de uma língua sobre a outra, sugerindo que "a maior parte do processamento lingüístico de uma pessoa seja realizado na língua dominante e que a outra língua seja usada apenas num nível superficial de produção e compreensão" (1986:11). Isso pode ser completamente inevitável, do ponto de vista da cognição humana, e pode talvez explicar por que mesmo os falantes mais proficientes de uma L2, em situações de extrema emoção ou pressão psicológica, acabam tendo um baixo desempenho na L2, ou pelo menos um desempenho inferior ao que teriam em situações de pouco estresse.

\section{CONCLUSĀO}

Este trabalho teve por objetivo apresentar a teoria de aquisição de segunda língua baseada na Hipótese da Gramática Universal. Inicialmente, foram relatados os principais aspectos relacionados ao escopo da Teoria Gerativa, introduzindo suas principais idéias. Em seguida, foram apresentados os principais pontos da teoria de aquisição de segunda língua baseada na GU, discorrendo-se sobre as questões controversas e sobre seus principais problemas. Por fim, tentou-se fazer uma discussão crítica de pontos obscuros da teoria, apresentando-se opiniões e soluções alternativas. Não se está 
propondo, contudo, nenhuma solução original definitiva. Como foi sugerido, a aquisição de uma segunda língua pode ser algo realmente muito complexo para comportar uma resposta única e abrangente. A pretensão deste trabalho restringe-se apenas à discussão de pontos inquietantes, na esperança de provocar novas pesquisas que ampliem o entendimento atual sobre o assunto e contribuam para o fortalecimento da Lingüística Aplicada enquanto ciência.

\section{NOTAS}

${ }^{1}$ Não se está fazendo aqui diferença entre segunda língua e língua estrangeira no que se refere ao contexto de aprendizagem/aquisição.

${ }^{2}$ Tradução minha, assim como todas as outras citações feitas a partir de autores estrangeiros, no restante deste trabalho.

${ }^{3}$ Teacher-talk se refere à fala simplificada do professor de língua estrangeira quando em interação com seus alunos e foreigner-talk à fala simplificada do nativo quando em interação com um estrangeiro.

${ }^{4} \mathrm{O}$ termo insiderse refere a um observador participante, ou seja, um pesquisador que não apenas observa o fenômeno estudado, mas que também participa dele ativamente.

${ }^{5}$ LAD é a abreviatura, em inglês, de Dispositivo de Aquisição de Língua (Language Acquisition Device), utilizada aqui por ser bastante conhecida no campo da Lingüística Aplicada.

\section{REFERÊNCIAS BIBLIOGRÁFICAS}

BLEY-VROMAN, Robert. What is the logical problem of foreign language learning? In: GASS, SCHACHTER (Ed. $\left.{ }^{5}\right), 1989$.

BEAUGRANDE, Robert de. Theory and Practice in Applied Linguistics: Disconnection, Conflict or Dialectic? Applied Linguistics, 18, 3, Oxford University Press, 1997.

CELANI, Maria Antonieta Alba. Afinal, o que é Lingüística Aplicada? In: PASCHOAL, Mara S. Z., CELANI, M. A. A. (Org.s) Lingüística Aplicada: da aplicação da Lingüística à Lingüística transdisciplinar. São Paulo: EDUC, 1992. 
COOK, Vivian. Linguistics and second language acquisition. London: Macmillan, 1993.

Universal Grammar and the learning and teaching of second languages.

In: ODLIN, Terence (Ed). Perspectives on pedagogical grammar. New York:

Cambridge University Press, 1994.

ELLIS, Rod. Understanding second language acquisition. Oxford: Oxford University Press, 1985.

. The study of second language acquisition. Hong Kong: Oxford University Press, 1994.

. Second language acquisition. Hong Kong: Oxford University Press, 1997.

FLYNN, Suzanne. The role of the head-initial/head-final parameter in the acquisition of English relative clauses by adult Spanish and Japanese speakers. In: GASS, SCHACHTER (Ed.s), 1989.

GARDNER, R., LAMBERT, W. Attitudes and motivation in second language learning. Rowley, Mass.: Newbury House, 1972.

GASS, Susan M. How do learners resolve linguistic conflicts? In: GASS, SCHACHTER (Ed. $\left.{ }^{s}\right), 1989$.

GASS, Susan M., SCHACHTER, Jacquelyn (Ed.s) Linguistic perspectives on second language acquisition. New York: Cambridge University Press, 1989.

GREGG, Kevin R. Krashen's Monitor and Occam's Razor. Applied Linguistics, 5, 2, Oxford University Press, 1984.

Second language acquisition theory: the case for a generative perspective. In: GASS, SCHACHTER (Ed.s), 1989.

. Taking explanation seriously; or, let a couple of flowers bloom. Applied Linguistics, 14, 3, Oxford University Press, 1993.

HYMES, D. H. On Communicative Competence. In: PRIDE, J. B., HOLMES J. $\left(\right.$ Ed. $\left.^{s}\right)$. Sociolinguistics. Harmondsworth, England: Penguin, 1972.

KAPLAN, Robert B. Applied Linguistics, the state of the art: is there one? English Teaching Forum, April, 1985.

. TESOL and Applied Linguistics in North America. TESOL Quaterly 25th Anniversary Collection, 1993.

KLEIN, Wolfgang. Second language acquisition. Cambridge: Cambridge University Press, 1986.

KRASHEN, Stephen. The input bypotbesis: issues and implications. Hong Kong: Longman, 1985.

LARSEN-FREEMAN, Diane, LONG, Michael H. An introduction to second language acquisition research. New York: Longman, 1991. 
LICERAS, Juana M. On some properties of the "pro-drop" paraeter: looking for missing subjects in non-native Spanish. In: GASS, SCHACHTER (Ed.), 1989.

LONG, Michael $\mathrm{H}$. The least a second language acquisition theory needs to explain. TESOL Quarterly, 24:4, 1990.

Assessment strategies for second language acquisition theories. Applied Linguistics, 14, 3, Oxford University Press, 1993.

McLAUGHLIN, Barry. Theories of second language acquisition. London: Edward Arnold, 1987.

SCHACHTER, Jacquelyn. Testing a proposed universal. In: GASS, SCHACHTER (Ed. $\left.{ }^{s}\right), 1989$.

VAN LIER, Leo. Forks and hope: pursuing understanding in different ways. Applied Linguistics, 15, 3, Oxford University Press, 1994.

VITRAL, Lorenzo. Princípios e parâmetros: pressupostos filosóficos da Gramática Gerativa. In: BRITO, Adriano N., VALE, Oto Araújo (Org. ${ }^{\text {) }) . ~ F i l o s o f i a, ~ L i n g u ̈ i s t i c a, ~}$ Informática: aspectos da linguagem. Goiânia: Editora da UFGO, 1998.

WIDDOWSON, H. G. Linguistics. Hong Kong: Oxford University Press, 1996.

WHITE, Lydia. Universal Grammar and second language acquisition. Amsterdam/ Philadelphia: John Benjamins, 1989a.

. The adjacency condition on case assignment: do L2 learners observe the Subset Principle? In: GASS, SCHACHTER (Ed.s), 1989b. 